\title{
Dr. Gustavo F. Grgicevic. In memoriam
}

\author{
Dr. Gustavo F. Grgicevic. In memoriam
}

REVISTA ARGENTINA DE CIRUGÍA PLÁSTICA 2019;25(2):101. HTTPS://DOI.ORG/10.32825/RACP/201902/0101-0101

Nació en la ciudad de Santiago del Estero, creció y estudió en Rosario, Santa Fe, hasta terminar el colegio secundario.

Posteriormente se trasladó a la ciudad de Corrientes. Allí ingresó a la Facultad de Medicina de la Universidad Nacional del Nordeste (UNNE), en la que se recibió de médico. También obtuvo el doctorado en Anatomía Descriptiva y Topográfica.

Fue profesor de la cátedra de Anatomía y Metodología de la UNNE.

Obtuvo el título de Especialista en Cirugía Plástica Estética y Reparadora en el Hospital Militar Central "Cirujano Mayor Dr. Cosme Argerich".

Una de sus pasiones era la "operación sonrisa". Además fue payamédico: su personaje favorito era "el mago surubí".

Adoraba viajar. Operaba niños figurados en todas partes del mundo.

Fue miembro SACPER, SCPNEA, ISAPS, FILACP, y Editor de la RACP en el período 2016-2019.

Papá de Tomás (24) y de Iván (33).

Buen colega, buen amigo, generoso, solidario, viajado, filántropo.

Sus colegas y amigos hoy lo recordamos con cariño, y le dedicamos esta edición .

Dra. Georgia Martínez

Editora de la Revista Argentina de Cirugía Plástica 